\title{
Dissolution Mechanism of Upconverting
}

\author{
$\mathrm{AYF}_{4}: \mathrm{Yb}, \mathrm{Tm}(\mathrm{A}=\mathrm{Na}$ or $\mathrm{K})$ Nanoparticles in
}

\section{Aqueous Media}

\section{Supporting Information}

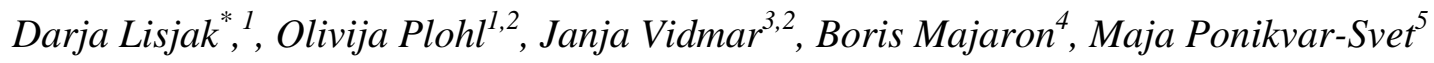

${ }^{1}$ Department for Materials Synthesis, Jožef Stefan Institute, Jamova 39, SI-1000 Ljubljana,

Slovenia

${ }^{2}$ Jožef Stefan International Postgraduate School, Jamova 39, SI-1000 Ljubljana, Slovenia

${ }^{3}$ Department of Environmental Sciences, Jožef Stefan Institute, Jamova 39, SI-1000 Ljubljana,

Slovenia

${ }^{4}$ Department of Complex Matter, Jožef Stefan Institute, Jamova 39, SI-1000 Ljubljana, Slovenia

${ }^{5}$ Department of Inorganic Chemistry and Technology, Jožef Stefan Institute, Jamova 39, SI-

1000 Ljubljana, Slovenia 

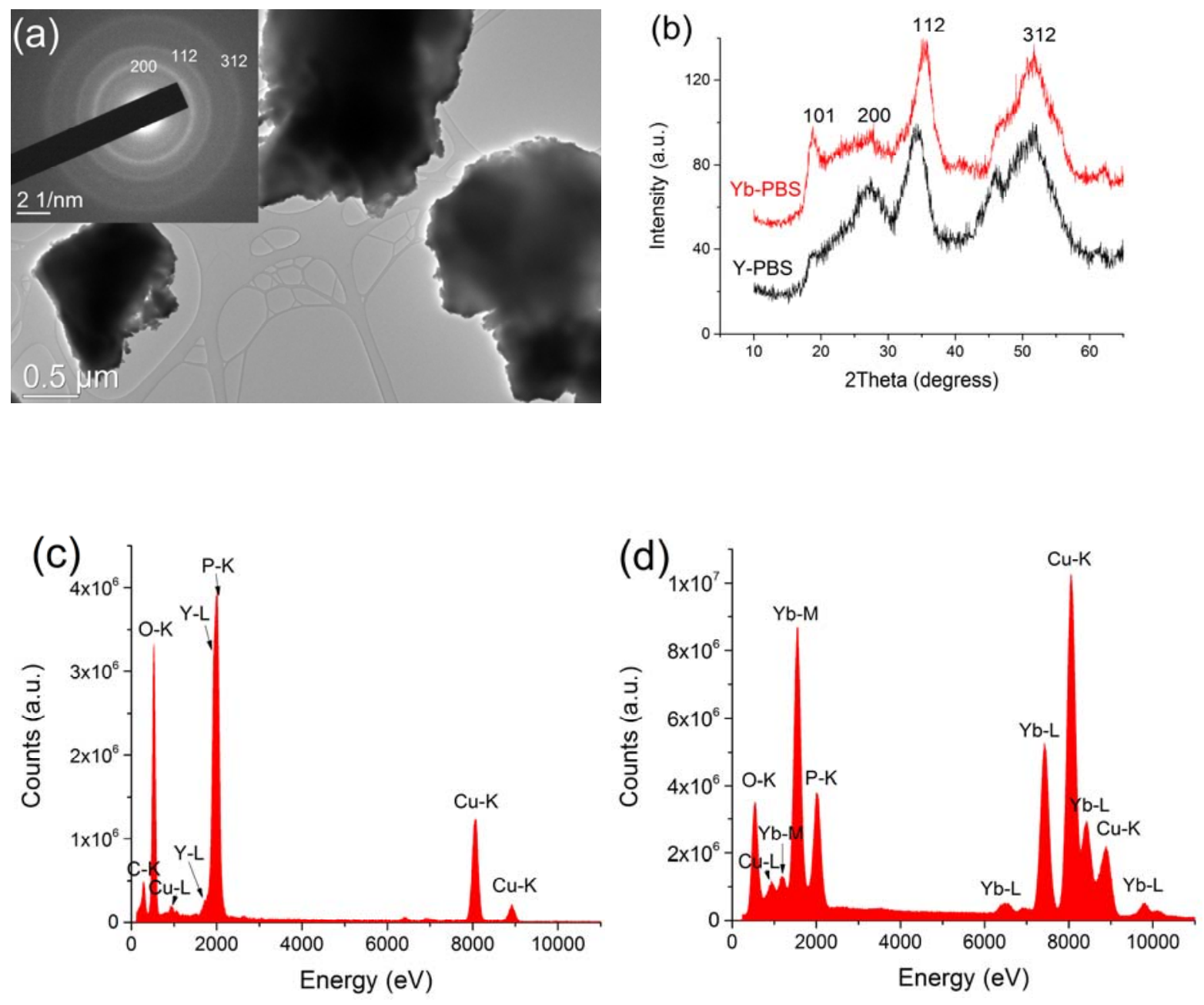

Figure S1. TEM image of Yb-PBS precipitates with the corresponding SAED (a), XRD patterns of Y-PBS and Yb-PBS (b), and EDXS spectra of Y-PBS (c) and Yb-PBS (d). The indices in (a) and (b) correspond to the space group I4 $1 /$ amd (141). 


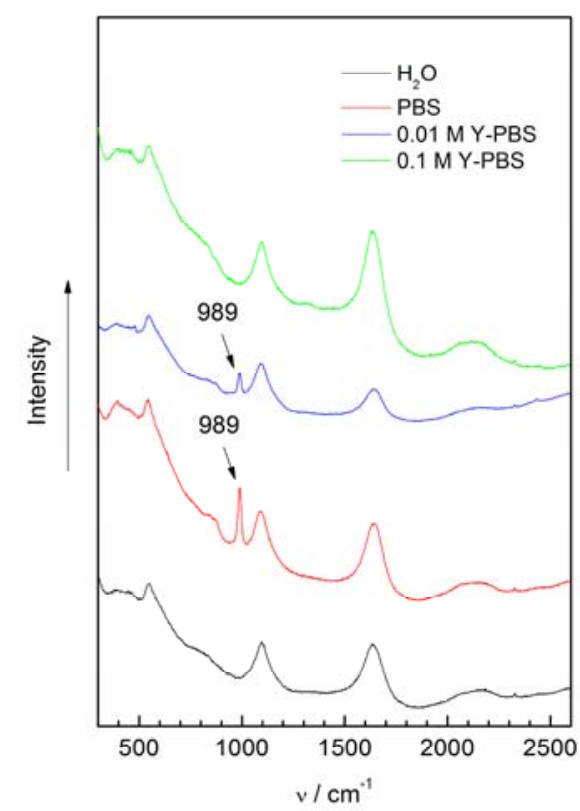

Figure S2. Raman spectra of Y-PBS precipitates and water.

\section{Estimation of the potential cytotoxic effect of UCNPs due to the released $\mathrm{F}^{-}$}

In our estimation we assume a retention time for the UCNPs in a body up to 3 days, a similar effect of the media as observed in PBS at $\mathrm{pH}$ of 7.4 (i.e., the worst-possible scenario), the minimum concentration of $\mathrm{F}^{-}$for the cytotoxic effect of $3 \mathrm{mM}^{1,2}$ and a spherical cell with a diameter of $5 \mu \mathrm{m}$. The resulting number of UCNPs inside a cell that could cause a cytotoxic effect is listed in Table S1. Although the K-UCNPs show a higher solubility rate and degree than the Na-UCNPs, the latter may be just as problematic in terms of cytotoxicity. Due to their larger sizes a smaller number of Na-UCNPs $\left(10^{3}-10^{4}\right)$ internalized into a cell than that of the KUCNPs $\left(10^{4}-10^{5}\right)$ would be cytotoxic. It is questionable whether such a large number of UCNPs can be internalized in a single cell in vivo. Nevertheless, the calculated cell volume fraction occupied by the "toxic" number of UCNPs would be insignificant (Table S1). 
Table S1. Minimum conditions for a possible cytotoxic effect by $\mathrm{F}^{-}$based on the $X_{F}$ of UCNPs at $37^{\circ} \mathrm{C}$ in PBS with a $\mathrm{pH}$ of 7.4 .

\begin{tabular}{|l|l|l|l|}
\hline sample & $\begin{array}{l}\text { Dissolution time } \\
\text { (h) }\end{array}$ & $\begin{array}{l}\text { Number of } \\
\text { UCNPs in a cell }\end{array}$ & $\begin{array}{l}\text { Volume fraction } \\
\text { of a cell (\%) }\end{array}$ \\
\hline \multirow{3}{*}{ Na-UCNPs } & 1 & $4 \times 10^{4}$ & 0.01 \\
\cline { 2 - 4 } & 24 & $8 \times 10^{3}$ & 0.003 \\
\cline { 2 - 4 } & 72 & $4 \times 10^{3}$ & 0.001 \\
\hline \multirow{3}{*}{ K-UCNPs } & 1 & $4 \times 10^{5}$ & 0.008 \\
\cline { 2 - 4 } & 24 & $9 \times 10^{4}$ & 0.002 \\
\cline { 2 - 4 } & 72 & $5 \times 10^{4}$ & 0.001 \\
\hline
\end{tabular}

\section{REFERENCES}

1. Agalakova, N. I.; Gusev, G. P. Molecular Mechanisms of Cytotoxicity and Apoptosis Induced by Inorganic Fluoride. ISRN Cell Biol., 2012, 2012, 403835, 16pp.

2. Babier, O.; Arreola-Mendoza, L.; Del Razo, L. M. Molecular mechanisms of fluoride toxicity. Chem. Bio. Inter., 2010, 188, 319-333. 